\title{
تداعيات جائحة كورونا وأثرها على العوائد المصرية من النقد الأجنبي
}

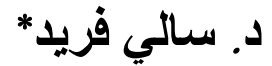

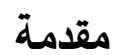

أحرزت مصر معدل نمو اقتصادي تجاوز ه\% على مدى العامين الماضيين، وسجلت مؤشرات

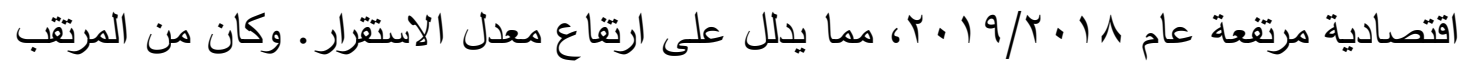
أن تؤدي الجهود الرامية إلى النهوض بمناخ الأعمال في مصر لمزيد من النمو الاقتصادي عام

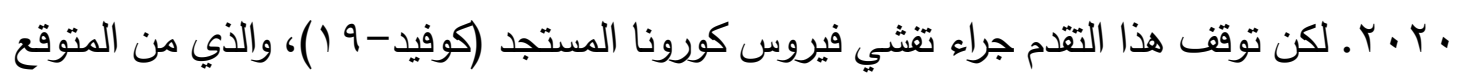
أن ينجم عنه تباطؤ الاقتصاد العالمي وما لذلك من تداعيات على الوضع الاقتصادي في مصر . تهدف هذه الورقة إلى بحث مختلف مصادر مصر من النقد الأجنبي، ومدى تطور هذه المصادر، وتداعيات كورونا والآثار المتوقعة على العوائد المصرية من النقد الأجنبي، وتحديد الإجراءات التي اتخذتها الحكومة لمواجهة الأزمة، واليُبل التي من المكن اتخاذها للحد من تداعيات كورونا، وذلك

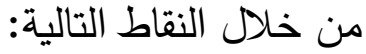

أولاً: تطور مصادر النقد الأجنبي في مصر ثانياً: تداعيات كورونا المتوقعة على مصادر النقد الأجنبي ثالثاً: الإجراءات التي اتخذتها الحكومة للتعامل مع الأزمة رابعاً: سياسات يمكن اتخاذها للحد من تداعيات كورونا

أولاً: تطور مصادر النقد الأجنبي في مصر يؤثر انتشار وباء كورونا بالسلب على مصادر مصر من النقد الأجنبي، ويشمل ذلك عائدات السياحة ومتحصلات الصادرات والاستثمار الأجنبي المباشر وتحويلات العاملين بالخارج وإيرادات قناة السويس. وفيما يلي يتم تتاول هذه البنود بمزيد من التحليل: 


\section{1 - عوائد قطاع السياحة}

يعرض الثكل التالي الإيرادات السياحية التي تحقتت في مصر خلال الفترة (2010-2019): شكل رقم (1): الإيرادات السياحية خلال الفترة (2010 - 2019) بالمليار دولار

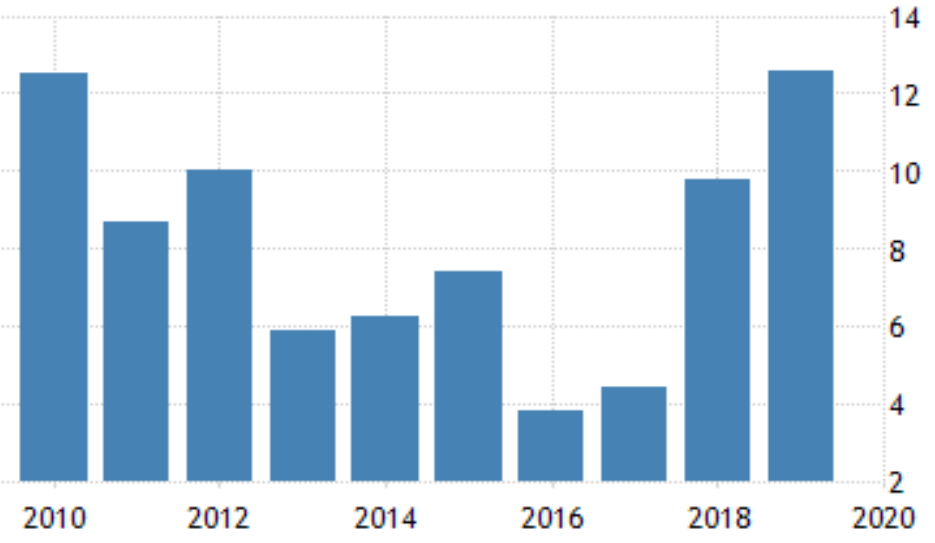

Source: Egypt economic indicators - trading economics, http://tradingeconomics.com يتضح من الثكل رقم (1) ارتفاع الإيرادات السياحية بقيمة 2.7 مليار دولار لتصل إلى 12.57 إلى مليار دولار عام 2019 بالمقارنة ب 9.8 مليار دولار عام 2018. شكل رقم (2): الإيرادات السياحية كنسبة من متحصلات ميزان الخدمات

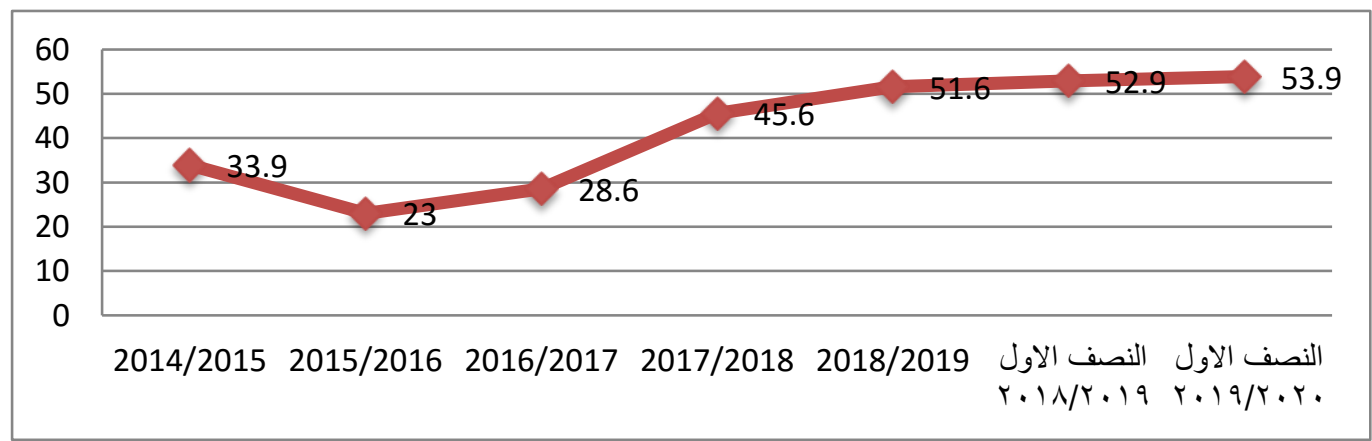

المصدر: بواسطة الباحث بالاعتماد على بيانات الجهاز المركزي للتعبئة العامة والاحصاء، www.capmas.org

يتضح من الشكل رقم (2) أن الإيرادات السياحية بلغت 53.9\% كنسبة من متحصلات الميزان الخدمي في النصف الأول من عام 2020/2019 بالمقارنة ب52.9\% في النصف الأول من عام 2019/2018. 
شكل رقم (3): تطور أعداد السائحين وفقا لطريقة الوصول

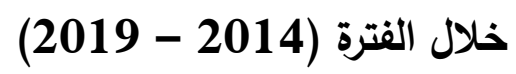

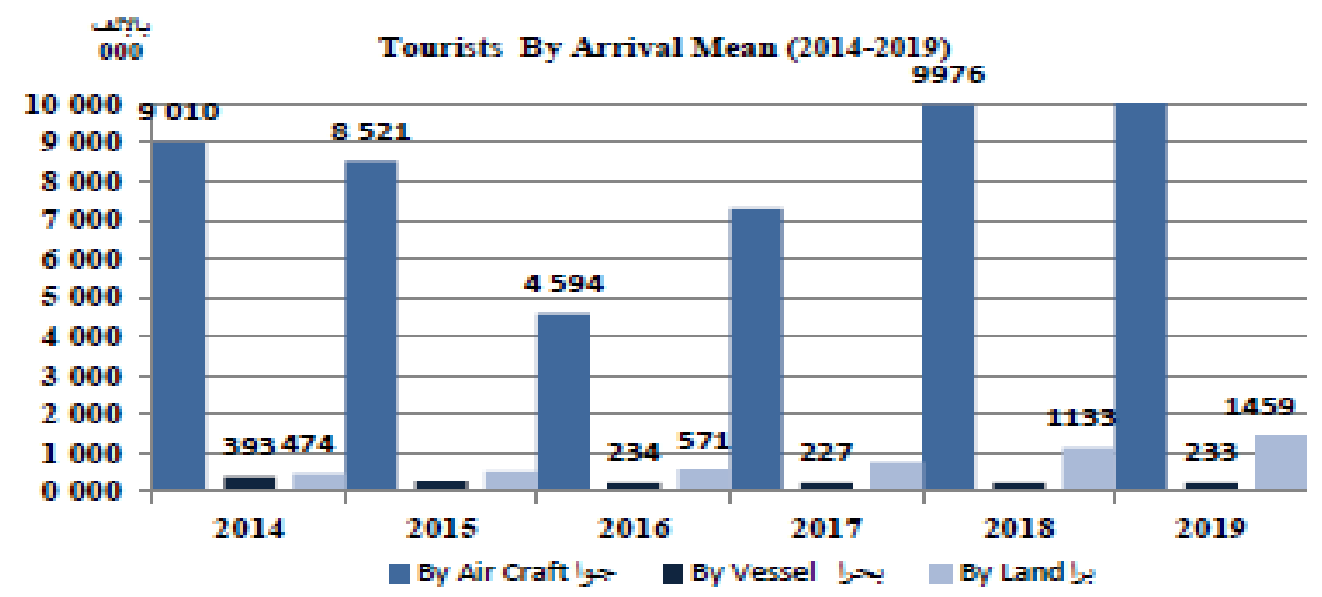

المصدر: الجهاز المركزي للتعبئة العامة والاحصاء، مصر في ارقام 2020

يتضح من الثكل رقم (3) أن عدد السائحين القادين إلى مصر باستخدام النقل الجوي بلغ 9.9 مليون سائح، واستخدم النقل البحري 1.4 مليون سائح، واستخدم النقل البري 233 ألف سائح عام .2019

جدول رقم (1): تطور أعداد السائحين وفقا لمجموعات الدول خلال الفترة (2014 - 2019) العدد بالألف

\begin{tabular}{|c|c|c|c|c|c|c|}
\hline 2019 & 2018 & 2017 & 2016 & 2015 & 2014 & مجموعات الدول \\
\hline 8381 & 6948 & 4672 & 2586 & 6794 & 7578 & الاتحاد الأوروبي \\
\hline 64.3 & 61.2 & 56.3 & 47.9 & 72.8 & 76.7 & $\%$ \\
\hline 3168 & 3039 & 2467 & 1962 & 1734 & 1625 & الدول العربية \\
\hline 24.3 & 26.8 & 29.7 & 36.3 & 18.6 & 16.4 & $\%$ \\
\hline 548 & 456 & 358 & 279 & 294 & 244 & الولايات المتحدة \\
\hline 4.2 & 4.0 & 4.3 & 5.2 & 3.2 & 2.5 & $\%$ \\
\hline 929 & 903 & 795 & 572 & 506 & 431 & أخرى \\
\hline 7.1 & 8.0 & 9.6 & 10.6 & 5.4 & 4.4 & $\%$ \\
\hline 13026 & 11346 & 8292 & 5399 & 9328 & 9878 & الإجمالي \\
\hline 100 & 100 & 100 & 100 & 100 & 100 & $\%$ \\
\hline
\end{tabular}

المصدر: الجهاز المركزي للتعبئة العامة والاحصاء، مصر في ارقام 2020 
يتضح من الجدول رقم (1) أن السائحين من الاتحاد الأوروبي يمثلون نحو 64.3\% من إجمالي السائحين الزائرين لمصر عام 2019، أما الدول العربية فتمثل 24.3\% من إجمالي السائحين.

$$
\text { 2- عوائد الصادرات }
$$

يعرض الثكل التالي تطور حجم التجارة الخارجية لدصر خلال الفترة (2014 - 2018):

شكل رقم (4): تطور حجم التجارة الخارجية خلال الفترة (2014 - 2018) بالمليار جنيه

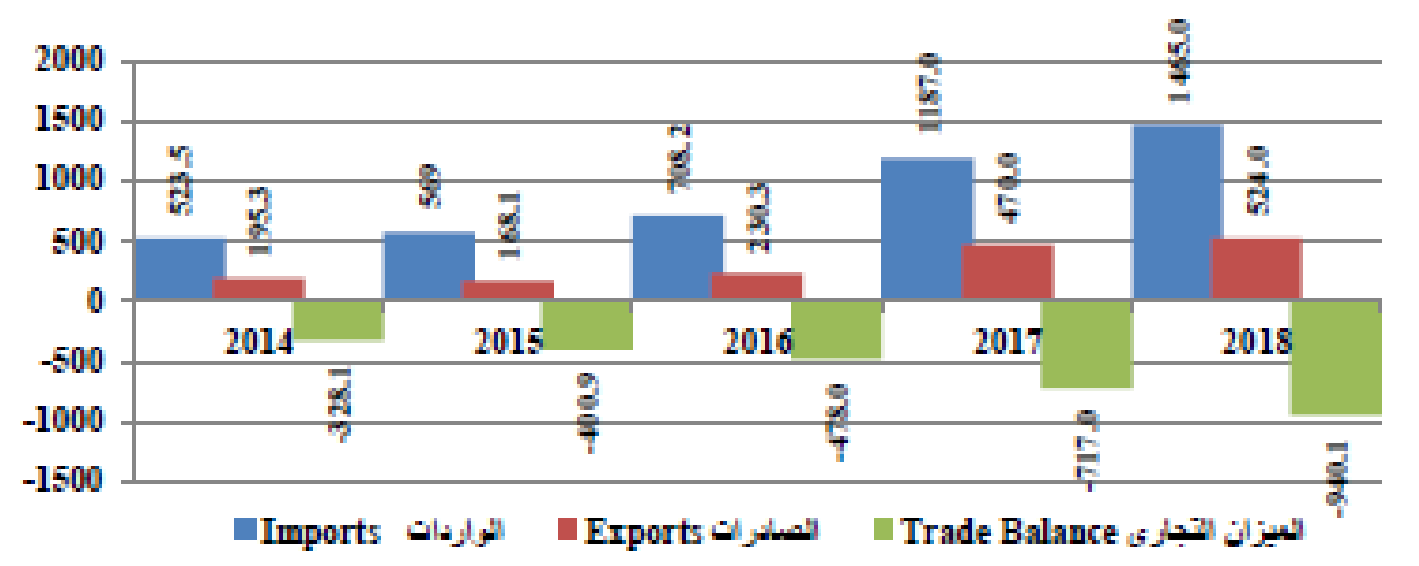

المصدر: الجهاز المركزي للتعبئة العامة والاحصاء، مصر في أرقام 2020

يتضح من الثكل رقم (4) أن قيمة الصادرات المصرية بلغت 524 مليار جنيه، أما الواردات فبلغت 1465 مليار جنيه عام 2018، لذا حقق الميزان التجاري عجزا بلغت قيمته 940 مليار جنيه عام 2019.

شكل رقم (5): تطور قيمة الصادرات خلال الفترة (أبريل 2019 - مارس 2020) بالمليون دولار

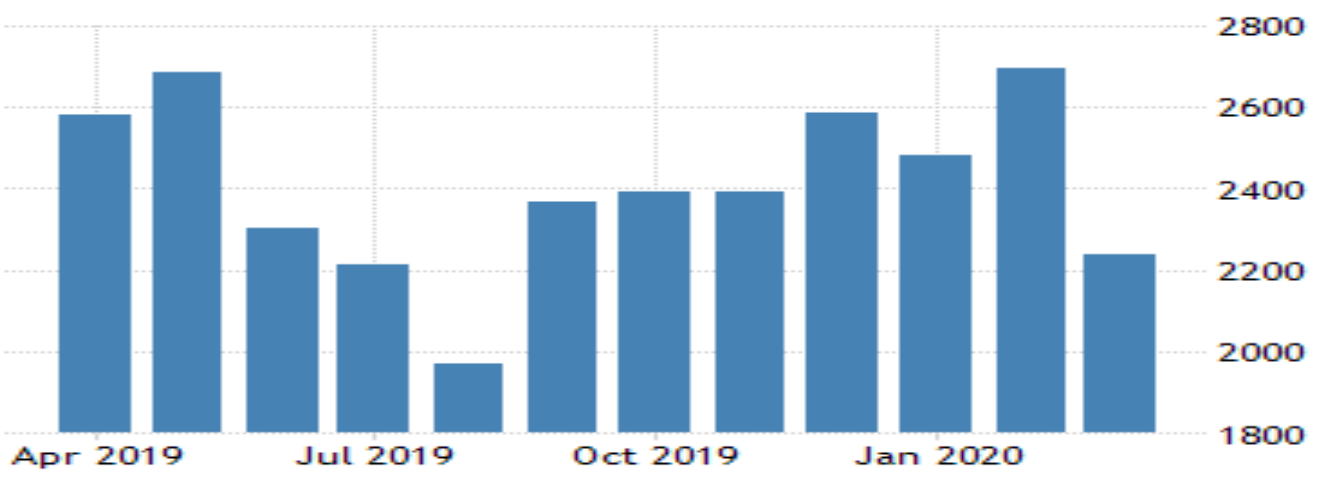

Source: Egypt economic indicators - trading economics, http://tradingeconomics.com 
يتضح من الشكل رقم (5) أن قيمة الصادرات المصرية انخفضت إلى 2238 مليون دولار في مارس 2020 في حين بلغت 2694 مليون دولار في فبراير 2020.

بلغت قيمة الصادرات النفطية 6.11 مليار دولار، بينما بلغت قيمة الواردات النفطية 5.11 مليار دولار عام 2019 تباع بسعر يعادل نسبة 19/20، بالإضافة إلى ذلك فإن جميع المنتجات البترولية تقريبًا (أوكتان 95 و 92 و 90 والسولار ) تحسب على أساس 100\% من التكلفة، باستثناء غاز البوتان، الذي خصصت الحكومة له دعمًا قدره 50 مليار جنيه في السنة المالية 2020/2019، وجدير بالذكر أن هذا الدعم قد ينخفض إلى 37 مليار جنيه، حيث كانت تقديرات

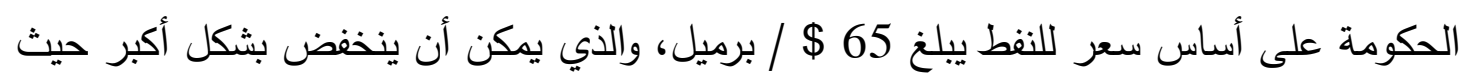
يبلغ المتوسط السنوي في الفترة المقبلة 54 \$ / برميل1 1 شكل رقم (6): تطور قيمة الواردات المصرية خلال الفترة (يناير 2019 - فبراير 2020)

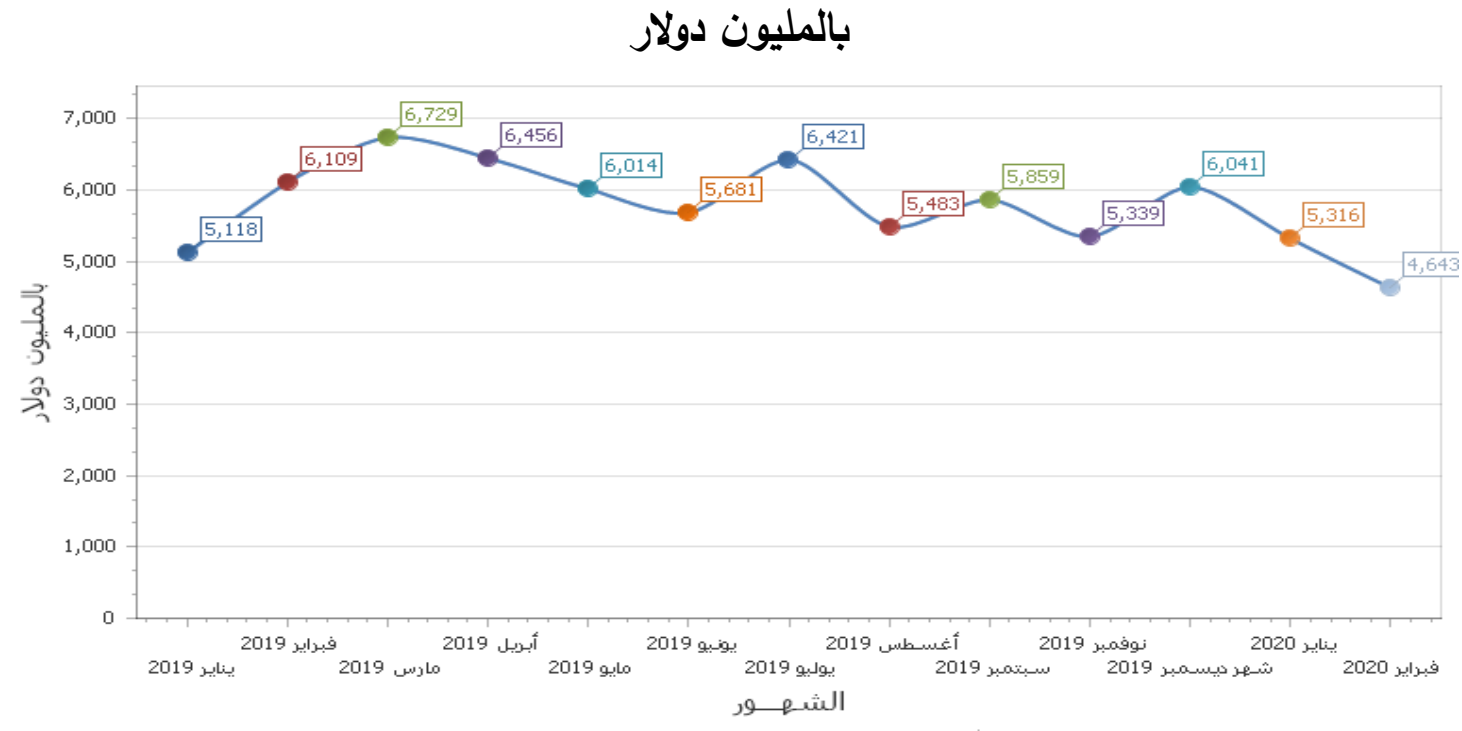

www.capmas.org المصدر: الجهاز المركزي للتعبئة العامة والاحصاء

يتضح من الثكل رقم (6) أن قيمة الواردات المصرية انخفضت إلى 4643 مليون دولار في فبراير 2020 في حين بلغت 5316 مليون دولار في يناير 2020. 
شكل رقم (7): الميزان التجاري خلال الفترة (أبريل 2019 - مارس 2020) بالمليون دولار

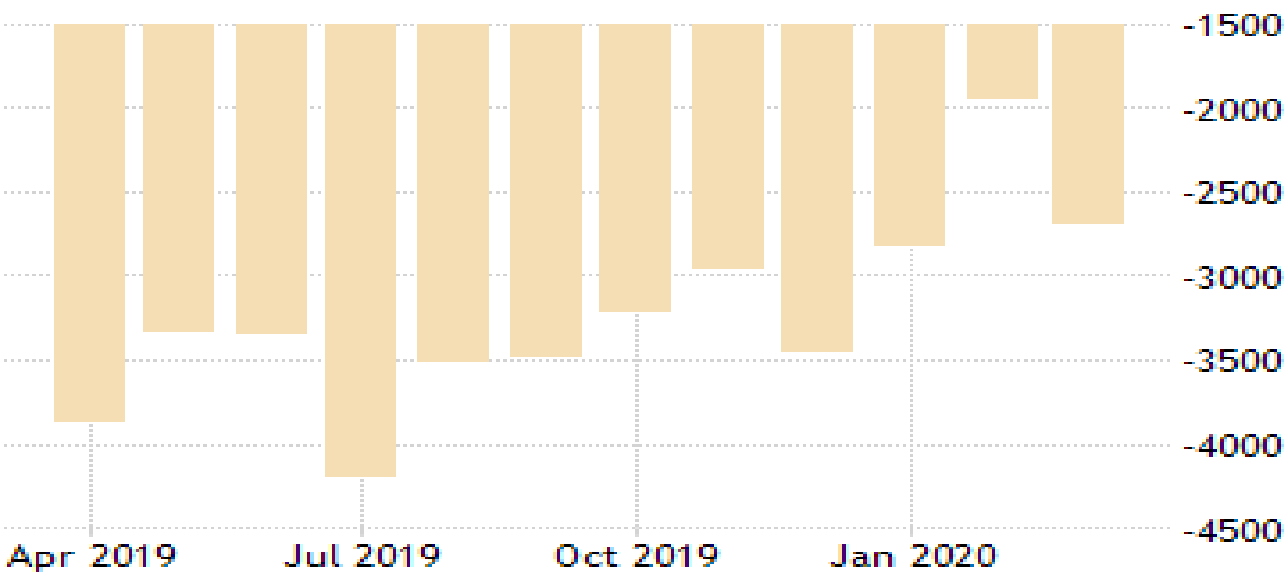

Source: Egypt economic indicators - trading economics, http://tradingeconomics.com يتضح من الثكل رقم (7) أن مصر حققت عجزًا تجاريًا بلغ 2693 مليون دولار في مارس .2020

شكل رقم (8): الحساب الجاري خلال الفترة (يناير 2017 - يناير 2020) بالمليون دولار

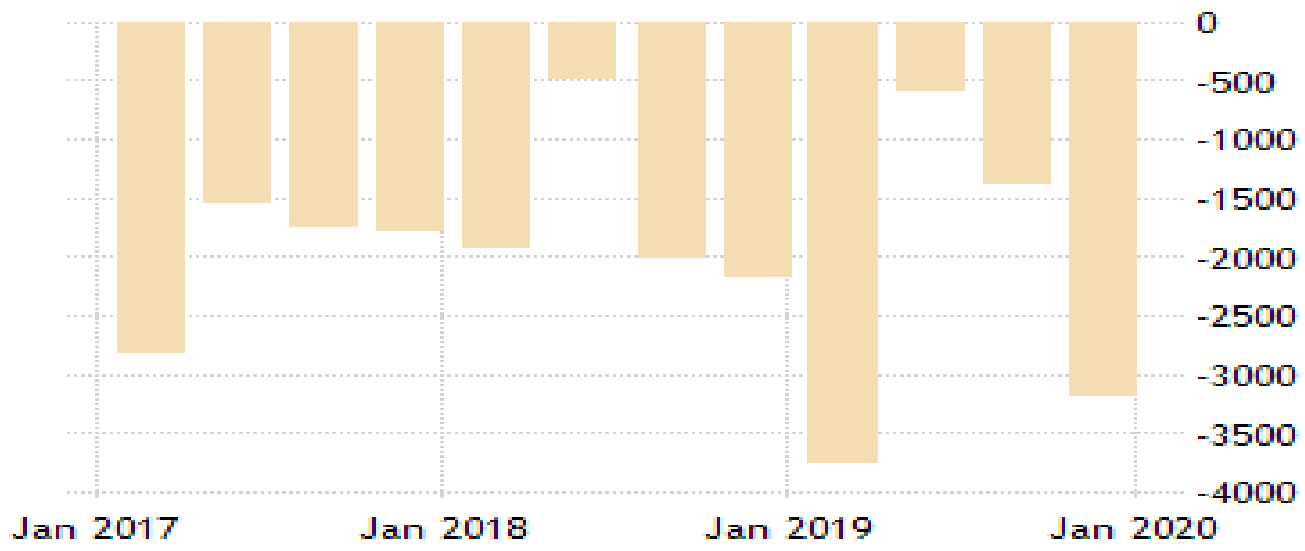

Source: Egypt economic indicators - trading economics, http://tradingeconomics.com يتضح من الثكل رقم (8) أن مصر حقت عجزاً في الحساب الجاري بلغ 3192 مليون دولار حتى يناير 2020.

لقد ارتفعت الصادرات الدصرية غير البترولية خلال الربع الأول من العام الجاري 2020 بنسبة بلغت حوالي 2\%، لتصل لـ 6 مليار و 728 مليون دولار مقارنة بنحو 6 مليار و 580 مليون دولار 
خلال نفس الفترة من عام 2019، بينما شهدت الواردات تراجعاً كبيراً بنسبة بلغت حوالي 24\% حيث سجلت 13 ملياراً و814 مليون دولار، مقابل 18 ملياراً و 233 مليون دولار خلال نفس الفترة من العام الماضي، وقد ساهمت هذه المؤشرات في انخفاض العجز في الميزان التجاري لمصر بقيمة 4 مليارات و 566 مليون دولار أي بنسبة تراجع بلغت 39\% عن نفس الفترة من عام

\section{شكل رقم (9): أهم الثركاء التجاريين للصادرات المصرية عام 2019}

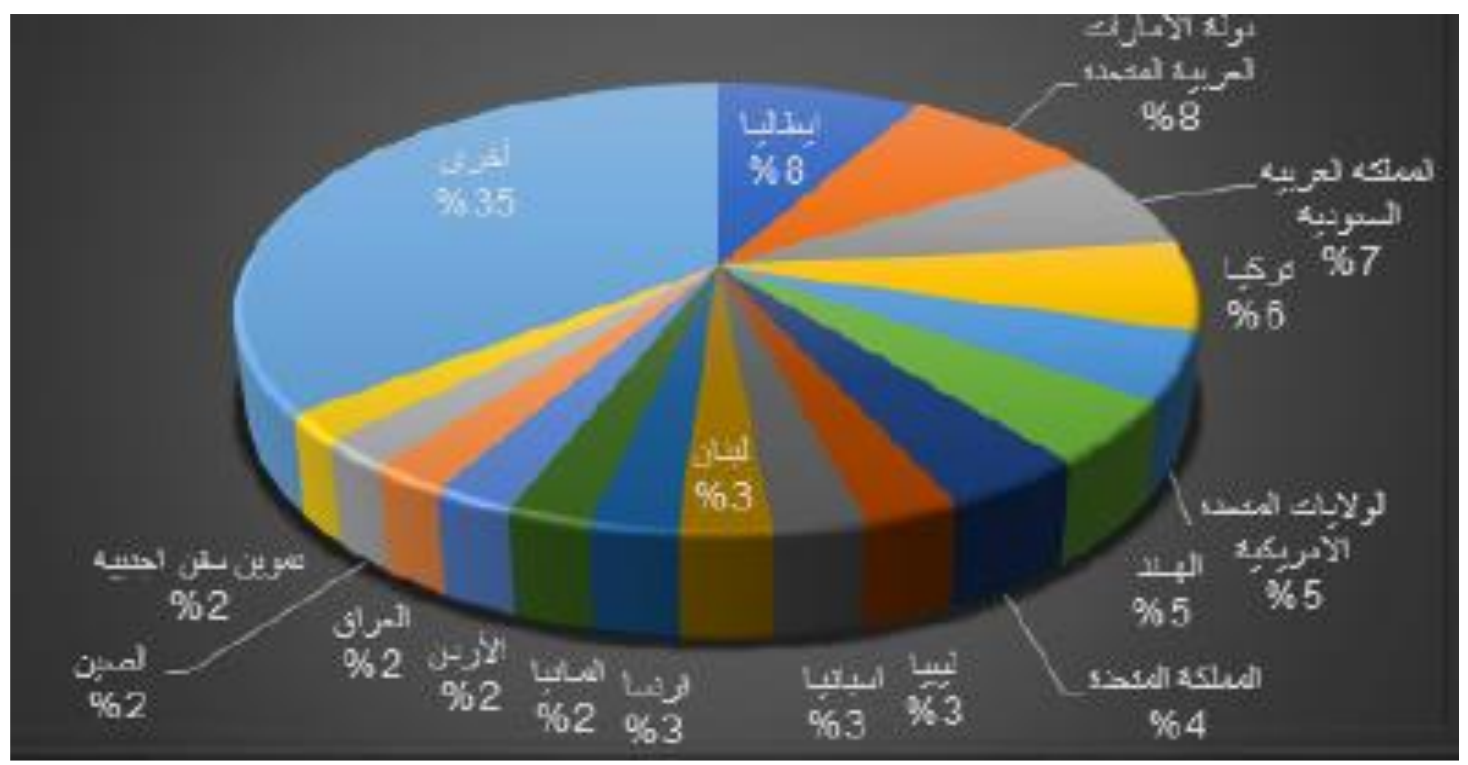

المصدر : الجهاز المركزي للتعبئة العامة والاحصاء، www.capmas.org

يتضح من الثكل رقم (9) وجود تركز في الأسواق التصديرية للمنتجات المصرية؛ حيث تبلغ الأهمية النسبية لأهم 15 سوقًا تصديريًا 62.61 \%، وتتمثل أهم هذه الأسواق في إيطاليا التي تعد أكبر شريك تجاري للصادرات المصرية داخل دول الاتحاد الأوروبي، ويُعزى ذلك إلى وجود اتفاقيات تجارية تساعد على دخول الصادرات المصرية للسوق الإيطالي بدون تعريفة جمركية، بالإضافة إلى سهولة الشحن من مصر إلى إيطاليا، فهنالك خطوط شحن عديدة إما بحرية عن طريق البحر المتوسط أو جوية. تليها الإمارات العربية المتحدة في المرتبة الثانية بنسبة 7.88 \% من إجمالي الصادرات المصرية، ويرجع ذلك إلى كون الإمارات مركز توزيع للسوق الخليجي فيتم من خلالها إعادة تصدير بعض المنتجات إلى دول الخليج وبعض الدول حول العالم، وتأتي 
المملكة العربية السعودية في المرتبة الثالثة كأكبر مستورد من مصر بنسبة 7\% من إجمالي الصادرات المصرية، تليها تركيا في المرتبة الرابعة بنسبة 6 \%؛ وتحتل الولايات المتحدة الأمريكية

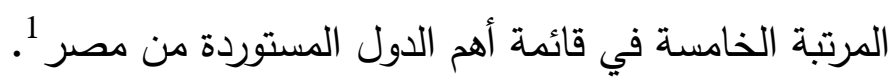

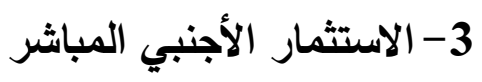

يعرض الشكل التالي تطور تدفقات الاستثمار الأجنبي المباشر للصر خلال الفترة (يناير 2017 - يناير 2020)

شكل رقم (10): تطور تدفقات الاستثمار الأجنبي المباشر خلال الفترة (يناير 2017 - يناير 2020) بالمليون دولار

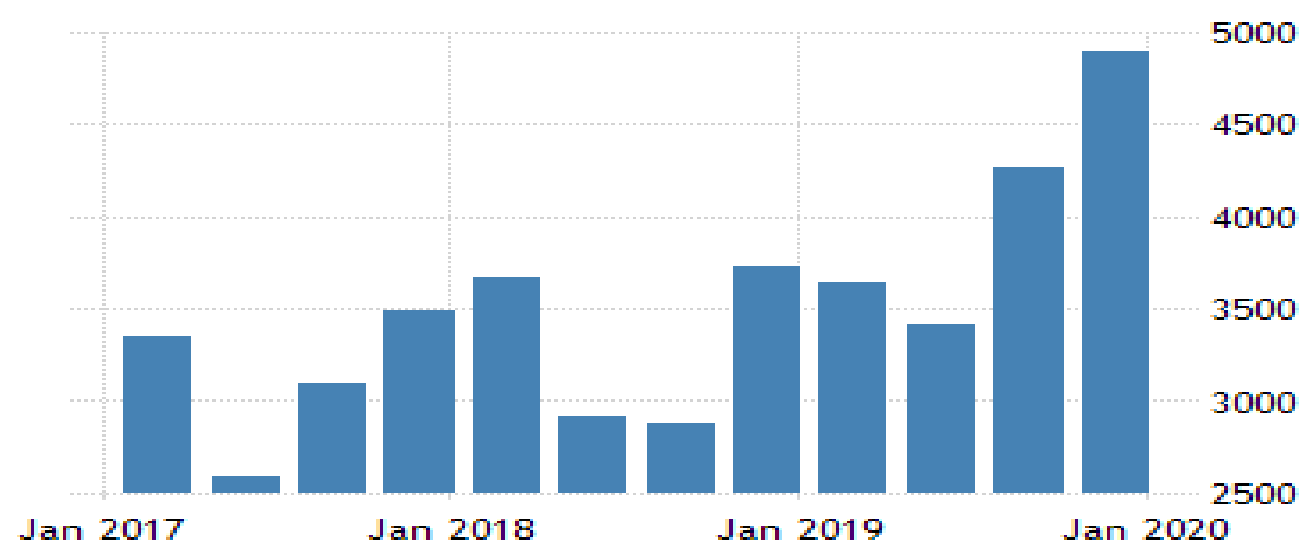

Source: Egypt economic indicators - trading economics, http://tradingeconomics.com يتضح من الثكل رقم (10) ارتفاع تدفق الاستثمار الأجنبي المباشر لدصر ليصل إلى 4899 مليون دولار حتى يناير 2020.

تعتبر الدول الأعضاء في الاتحاد الأوروبي والإمارات العربية المتحدة والكويت وقطر ، أهم مصادر الاستثمار الأجنبي المباشر في مصر، وتعتبر الصين مصدرا لنحو 2\% من تدفق الاستثار الأجنبي المباشر لمصر ـ أما عن التوزيع القطاعي فيستحوذ قطاع البترول على 74\% من تدفقات الاستثمار الأجنبي المباشر لمصر، يليه القطاع العقاري فيمثل 6\% ثم قطاع الصناعة التحويلية www.arkan-srp.com أسماء علي، التصدير في مصر السياسات والعوائق والفرص أركان للاراسات والأبحاث والنثر 
5.1\%، مما يعني أن هذه القطاعات الثلاثة هي الأكثر عرضة لتراجع تدفقات الاستثمار الأجنبي

$$
\text { المباشر لمصر نتيجة تداعيات أزمة كورونا1. }
$$

شكل رقم (11): حساب رأس المال خلال الفترة (يناير 2017 - يناير 2020) بالمليون دولار

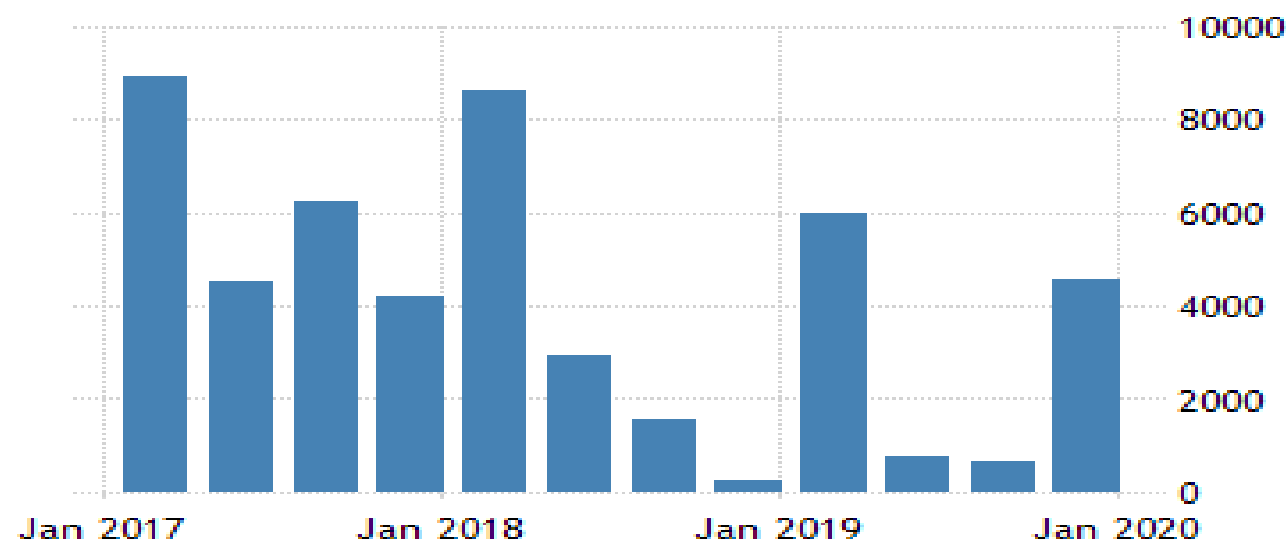

Source: Egypt economic indicators - trading economics, http://tradingeconomics.com يتضح من الثكل رقم (11) أن مصر سجلت فائضاً في حساب رأس المال بلغ 4576.20 مليون دولار حتى يناير 2020.

4- تحويلات العاملين بالخارج لمصر

يعرض الثكل التالي تطور قيمة تحويلات العاملين بالخارج لهصر خلال الفترة (يناير 2017 يناير 2020): شكل رقم (12): تحويلات العاملين بالخارج خلال الفترة (يناير 2017 - يناير 2020) بالمليون دولار

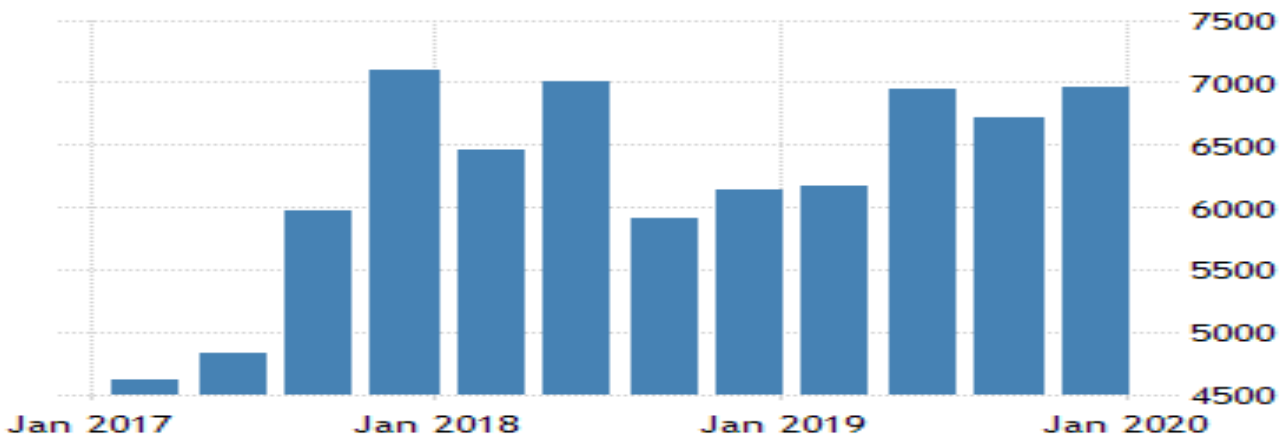

Source: Egypt economic indicators - trading economics, http://tradingeconomics.com www.gafi.gov.eg الهيئة العامة للاستثمار والمناطق الحرة 
يتضح من الشكل رقم (12) ارتفاع تحويلات العاملين في الخارج لمصر حيث بلغت 6963.90 مليون دولار حتى يناير 2020.

بلغ عدد المصريون المغتربين في الخارج 9.5 مليون شخص وفقا لإحصائيات الجهاز المركزي للتعبئة العامة والإحصاء، وتحظى الدول العربية بالنصيب الأكبر من العمالة المصرية بنحو 6.2 مليون شخص بنسبة 65.2 \%، بينما يقيم نحو 1.25 مليون شخص بنسبة 13.2 \% في الدول الأوروبية. ويوجد نحو 46.9 ألف مصري في الدول الأفريقية غير العربية، ويقيم نحو 14 ألفاً في البلدان الآسيوية، 25 \% منهم في الصين، بينما يقدر عدد المصريين في الولايات المتحدة بنحو مليون نسمة. ويتوزع المصريون في الدول العربية بين السعودية التي تحتل المرتبة الأولى في لهين بنحو 2.9 مليون شخص بنسبة 46.9 \% من المصريين المقيمين في الدول العربية، في حين

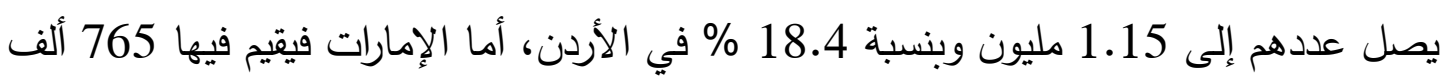
مصري بنسبة 12.3 \% 1 1.

وتسهم العمالة المصرية في الخارج في رصيد الاحتياطي من النقد الأجنبي، علاوة على أنها ترفع

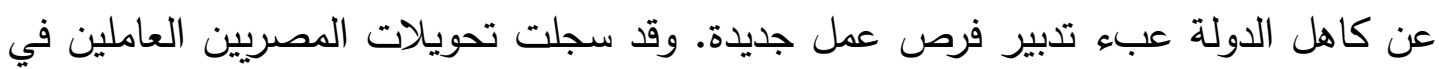

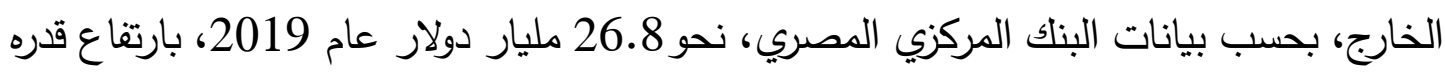

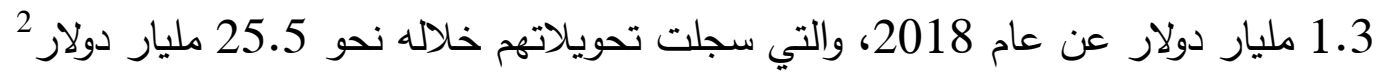
جدول رقم (2): نسبة الانخفاض في تحويلات العاملين بالخارج

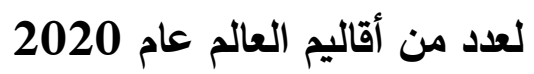

\begin{tabular}{|c|c|}
\hline نسبة الانخفاض في التحويلات \% & المنطقة \\
\hline 27.5 & أوروبا ووسط أسيا \\
\hline 23.1 & أفريقيا جنوب الصحراء \\
\hline 22.1 & جنوب أسيا \\
\hline 19.6 & الثرق الأوسطوشمال أفريقيا \\
\hline 19.3 & أمريكا اللاتينية والكاريبي \\
\hline 13.0 & شرق أسيا والباسيفيك \\
\hline
\end{tabular}

المصدر : تقديرات البنك الدولي www.worldbank.org أبريل 2020

1 1 الجهاز المركزي للتعبئة العامة والإحصاء، www.capmas.org

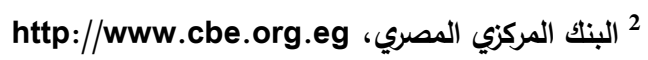


يشير الجدول رقم (2) أنه من المتوقع أن تتخفض التحويلات بنسبة 19,6 \% لتصل إلى 47 مليار دولار عام 2020 في منطقة الثرق الأوسط وشمال إفريقيا، ويرجع هذا الانخفاض المتوقع في التحويلات إلى تباطؤ الاقتصاد العالمي وانخفاض أسعار النفط في دول الخليج العربي. 5- 5 - 5 إيرادات قناة السويس يعرض الثكل التالي رقم (13) تطور إيرادات قناة السويس خلال الفترة (أبريل 2018 - أبريل :(2019

شكل رقم (13): تطور إيرادات قناة السويس خلال الفترة (أبريل 2018 - أبريل 2019)

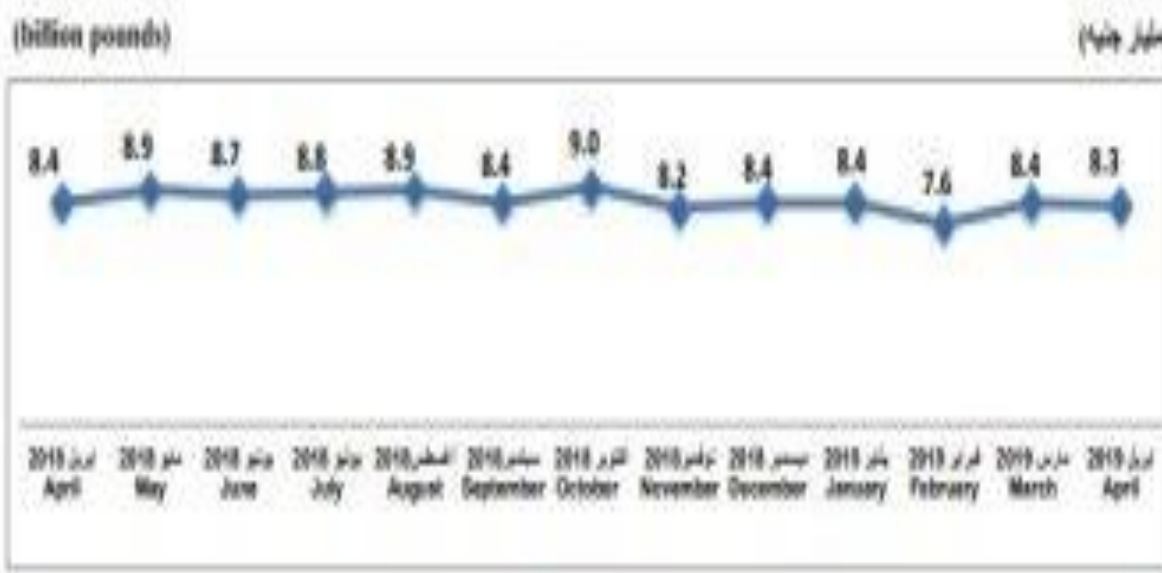

\section{Ma}

14. Number of Prasing Ships in Suez Conal

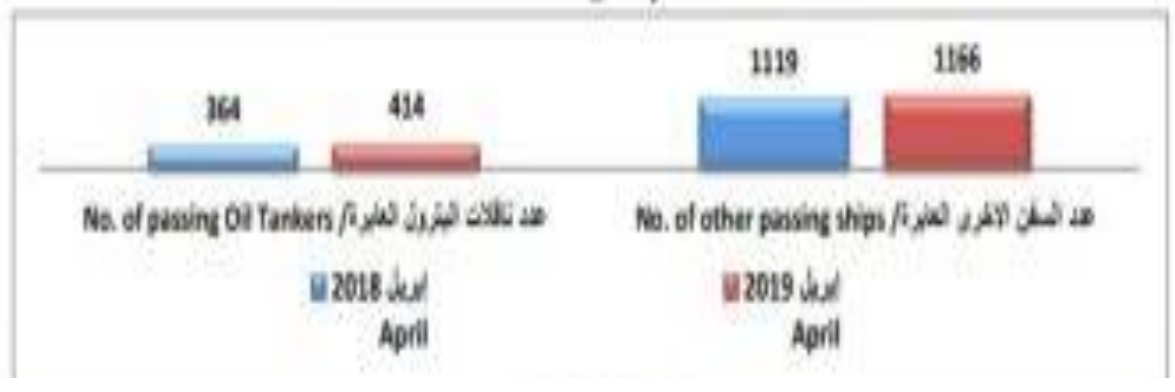

المصدر: الجهاز المركزي للتعيئة العامة والاحصاء، البئ

يتضح من الثكل رقم (13) عائد قناة السويس بلغ 8.4 مليار جنيه في مارس 2019، وانخفض

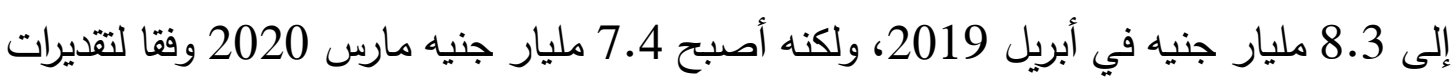
الجهاز المركزي للتعبئة العامة والإحصاء. 


\section{6- - 6 الاحتياطي من النقد الأجنبي}

بلغ صافي الاحتياطات الدولية لدى البنك المركزي المصري 45.5 مليار دولار في فبراير 2020 ، وانخفض إلى نحو 40.1 مليار دولار بنهاية مارس 2020 وهو يغطي نحو 8 أشهر من الواردات

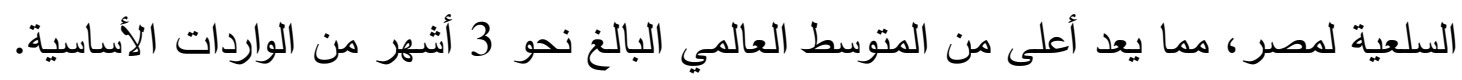

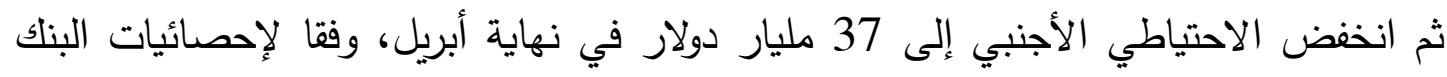

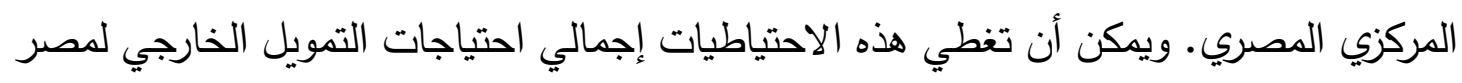
خلال عام 2020 والمقدرة بنحو 16 مليار دولار 1.

\section{ثانياً: تداعيات كورونا المتوقعة على مصادر النقد الأجنبي لمصر}

أوضحت وكالة موديز في تقرير لها أن الصدمة التي سبيتها تداعيات أزمة انتشار فيروس كورونا بالنسبة للاقتصاد المصري تتمثل بشكل رئيسي في الضغط على متلفيل فيلبات التمويل الخارجي،

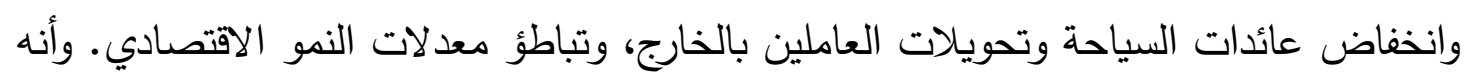

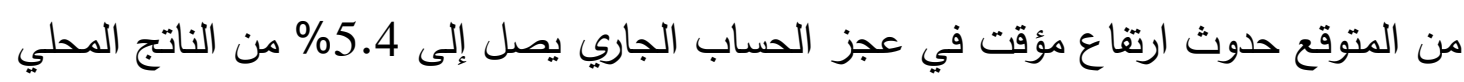

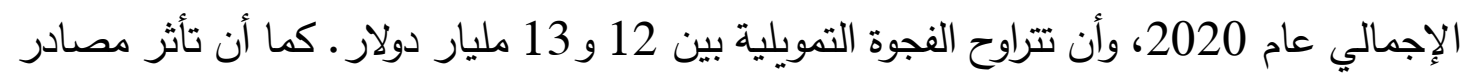
النقد الأجنبي حال استمراره حتى نهاية عام 2020، قد عقبة أمام عودة النشاط الاقتصادي بكامل

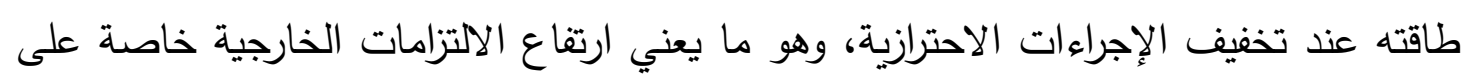
مستوى الواردات وبالأخص مستلزمات الإنتاج2.

أظهرت المؤشرات الأولية لموازنة العام المالي 2021/2020، والسيناريوهات التي أعدتها وزارة

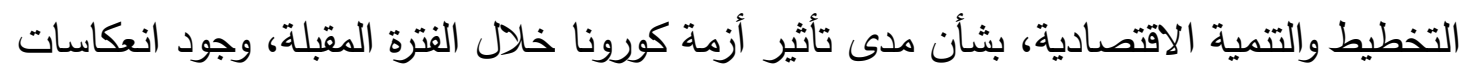

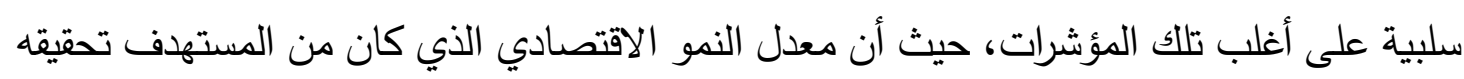

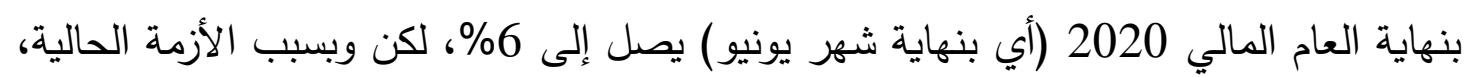

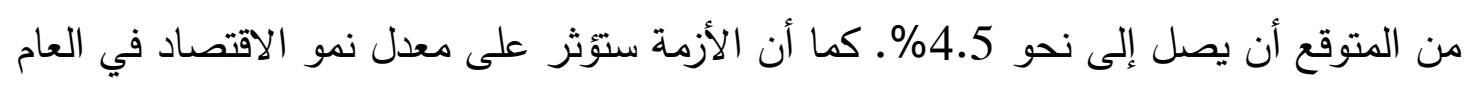

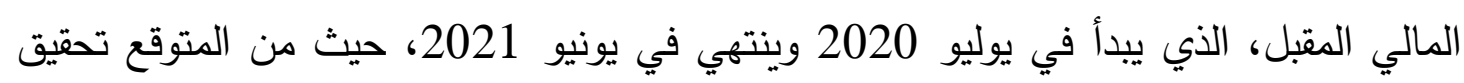

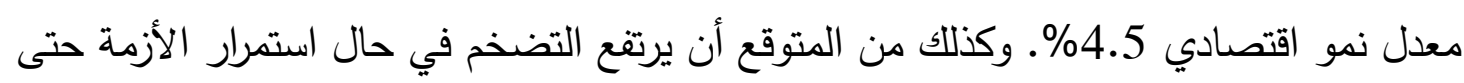
ديسمبر 2020، ليصل إلى 8.9\% نتيجة للطلب الزائد على بعض المنتجات ومحدودية زيادة الطاقة الإنتاجية في الأجل القصير، فضلاً عن صعوبة إحلال مستلزمات الإنتاج من الواردات3. 
وتعتبر الاستثمارات الكلية من أبرز المؤشرات التي ستتأثر سلبًا، حيث من المتوقع انخفاض حجم الاستثمارات الخاصة مما سيؤثر بدوره على حجم الاستثمارات الكلية، وفي حال استمرار الأزمة حتى منتصف العام المالي 2021/2020، ستخفض الاستثمارات الكلية من 960 مليار جنيه إلى 740 مليار جنيه، أي بانخفاض قدره 220 مليار جنيه، وبنسبة تراجع متوقعة 23\%. كما أن هناك العديد من القطاعات التي سوف تتأثر، منها قطاع السياحة والمطاعم، وقطاع الترفيه والخدمات العامة، مثل خدمات الغذاء والإقامة، فضلاً عن قطاعي الصناعة التحويلية، وتجارة الجملة والتجزئة، حيث أن كل المؤشرات تشير إلى أن الاقتصاد العالمي والاقتصاد المصري، سيشهدان فترة ليست قصيرة من الركود 1

ويتضح الأثر على مصادر النقد الأجنبي في مصر من خلال النقاط التالية: 1- الأثر على عوائد قطاع السياحة

إن انتشار فيروس "كورونا" يهدد قطاع السياحة ليس في مصر فقط ولكن على مستوى العالم، بدأت التداعيات تظهر خلال شهر فبراير 2020 على مؤشرات السياحة في مصر ، حيث تراجعت الأعداد والإيرادات لتسجل - 6\% و - 23\% على التوالي • وازدادت حدة الانخفاض في شهر مارس لتسجل تراجعاً بنسبة - 63\% في الأعداد و - 36\% في الإيرادات، وذلك أدى إلى تراجع مؤشرات الربع الأول لعام 2020 بنسبة - 19\% في أعداد السائحين الوافدين ونسبة - 11 \% في الإيرادات، وهذا يمثل خسائر تقدر بحوالي 295 مليون دولار مقارنة بذات الفترة من عام2019.20

ومع توقف حركة السياحة والطيران، من المتوقع أن تتخفض الإيرادات السياحية من أوروبا بنحو 4مليار دولار ، ومن الدول العربية بحوالي 1,8 مليار دولار • ومع انخفاض سقف التوقعات فيما يتعلق بسرعة التعافي من الركود العالمي، والذي يقدره صندوق النقد الدولي - 3\% في أبريل 2020 سيحتاج قطاع السياحة إلى بضعة أعوام حتى يعاود نشاطه. وتوقعت "سي آي كابيتال" انخفاض عائدات السياحة في مصر بمقدار يتراوح بين 2.5 و 3 مليار دولار في الربع الثاني من عام 2020. 
ولا يقتصر التأثير الناجم على تراجع الإنفاق السياحي فحسب ولكنه يمتد إلى صناعات الفنادق والمطاعم، ومشروعات سيارات الأجرة، والعاملين في مجال الإششاد السياحي، وأيضا تجهيز ومعالجة الأغذية، وقطاع الزراعة.

فقد أثارت دراسة لمنظمة العمل الدولية إلى تأثر حوالي 81\% من القوى العاملة العالمية بسبب الإغلاق الكلى أو الجزئي لأماكن العمل، وهو ما قد يفقد سوق العمل العالمي حوالي 200 مليون وظيفة، فمن المتوقع أن ما يقرب من 1.25 مليار شخص ممن يعملون في القطاعات الأشد تضررا بالجائحة، كالسياحة وخدمات الإقامة والطعام، والصناعات التحويلية، وتجارة التجزئة، وأنشطة الأعمال والأنشطة الإدارية والتي تشكل ما نسبته حوالي 38 \% من التوظيف العالمي، سيكونون عرضةً لمخاطر التسريح وتخفيض الأجور • وبالنسبة لمصر ، فإن القطاع غير الرسمي يستحوذ على نحو 50\% من المنشآت الاقتصادية، لذا فإن العاملين في القطاعات الأكثر تضرراً ربما يتعرضون لصدمات غير متوقعة في دخولهم؛ مما قد يتسبب في خفض قدراتهم الشرائية وبشكل خاص من المواد الغذائية. توقع الاتحاد الدولي للنقل الجوي، أن تؤدي أزمة فيروس كورونا إلى تكبد شركات الطيران خسائر قدرها 84 مليار دولار وتقليص الإيرادات إلى النصف عام 2020، وهو ما سيكون أسوأ عام في تاريخ القطاع • وأنه من المرجح أن تتخفض الإيرادات إلى الى 419 مليار دولار بدلا من 838 مليار دولار في عام 2019 مع توقف معظم الرحلات الجوية في أنحاء العالم. وفي عام 2021 يتوقع الاتحاد خسائر قدرها 15.8 مليار دولار ليصل إجمالي خسائر العامين 2020 و 2021 إلى نحو 100 مليار دولار، حيث تجد حركة السفر الجوي صعوبة في التعافي وتخفض شركات الطيران أسعارها، وأوضح أن قطاع الطيران في مصر تكبد

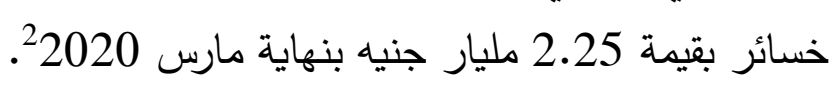

\section{2- الأثر على الصادرات}

قد يؤدي انتشار فيروس كورونا إلى اضطراب حركة التجارة وسلاسل التوريد، والتي قد تصل إلى الى صعوبة توفير بعض مكونات الإنتاج وقطع الغيار، وقد يواجه الموردون صعوبات في التوريد. ومن المتوقع أن يؤدي تباطؤ الطلب العالمي إلى انخفاض الصادرات المصرية، كما أن إجراءات

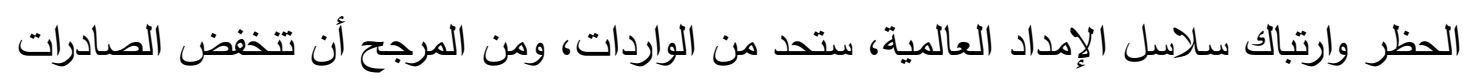
المصرية بنسبة أكبر من الانخفاض في الواردات، فيزداد العجز في الميزان التجاري3. 
وأشار تقرير غرفة التجارة الأمريكية بالقاهرة إلى تراجع عائدات التصدير لمصر بنسبة 25\% عام 2020، حيث أن أكبر الثركاء التجاريين لمصر هم الاتحاد الأوروبي وإيطاليا والإمارات والسعودية والولايات المتحدة الأمريكية والصين وتركيا، وهي من بين الاقتصادات التي تأثرت بالوباء. فقد أوققت هذه البلدان نشاطها الصناعي مما سيكون له آثاراً سلبية مباشرة على التجارة من الاتجاهين. فعلى صعيد التصدير ، تواجه حركة الصادرات إلى الاتحاد الأوروبي - خاصة إيطاليا والولايات المتحدة - تأخيرات داخلية وخارجية، مما سيؤثر أيضًا على الحسابات الخارجية. وبالمثل، من المرجح أن تستورد مصر كميات أقل، حيث يركز الموردون بالخارج على الأسواق المحلية؛ مما سيؤثر على عدد من الشركات المصنعة في مصر، خاصة في قطاعات الأجهزة الكهربائية والإلكترونية والمنسوجات التي تعتمد بشكل كبير على مستلزمات الإنتاج المستوردة.

\section{3- الأثر على الاستثمارات الأجنبية}

تسببت الأزمة في خروج المزيد من استثمارات المحافظ الأجنبية، لُتسجل حوالي 8 - 10 مليار دولار وذللك خلال الفترة من 20 فبراير حتى بداية يونيو 2020، ومن المتوقع حدوث انخفاض من محتمل في الاستيراد، وبالتالي تراجع منحنى التكلفة. وقد يسعى بعض المستثرين في أسواق الأسهر إلى خروج رأس المال من مصر لتسوية خسائرهم في الأسواق العالمية، مما يؤدي إلى تراجع أسعار صرف العملة المحلية؛ مما يعني تحمل الحكومة لأعباء إضافية قد تؤدي إلى لى إلى إلى مشكلات في سداد أقساط وأعباء خدمة الديون الخارجية ويشدد الشروط الائتمانية للحصول على

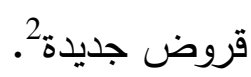

إن ديون وتدفقات الأسهم الخارجة من الأسواق العالمية الناشئة بلغت نحو 78 مليار دولار في الشهرين التاليين منذ بدء أزمة كورونا بالتزامن مع اندفاع المستثرين نحو الاستثمار في أصول

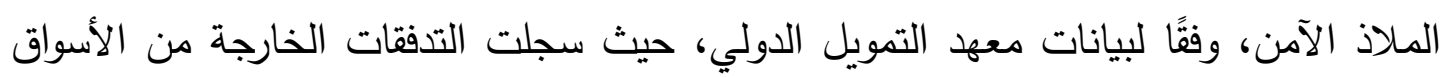
الناشئة خلال شهري يناير وفبراير 2020 أكثر من ثلاثة أضعاف المبلغ الذي شوهد في الأشهر الثلاثة التالية لبداية الأزمة المالية العالمية في 2009/20083.

$$
\text { 4- الأثر على تحويلات العاملين بالخارج }
$$

يوجد نحو 65\% من المصرين العاملين بالخارج في دول الخليج، ومع هبوط أسعار النفط العالمية، وما تتعرض له دول الخليج من ضغوط مالية كبيرة نتيجة فيروس كورونا، يتوقع انخفاض تحويلات

American chamber of commerce in Egypt http://www.amcham.org.eg 1 www.gafi.gov.eg الهيئة العامة للاستثمار والمناطق الحرة 2

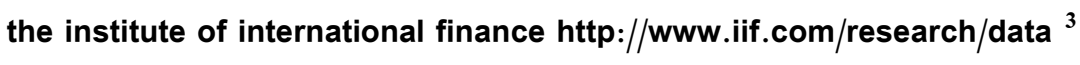


العاملين بالخارج بنسبة 10\% بنهاية يونيو 2020، وفقا لتقديرات البنك الدولي ـ ـومن المرجح أن

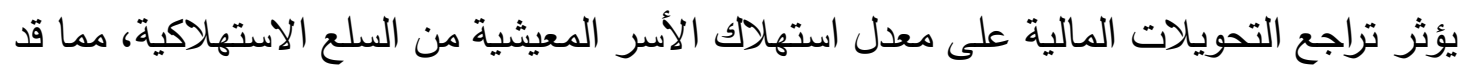
يؤدي إلى تضرر قطاعات إنتاج السلع الوسيطة.

أشار تقرير لمؤتمر الأمم المتحدة للتجارة والتتمية (أونكتاد) خلال شهر مارس2020 أن تراجع

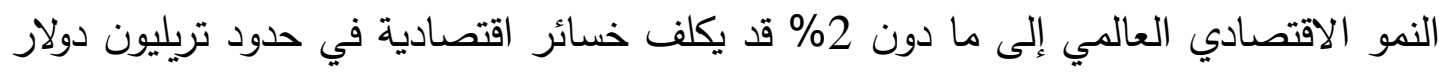

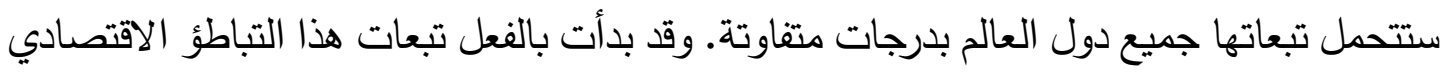

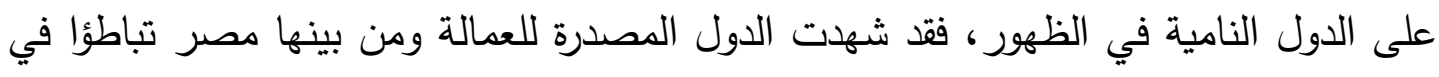

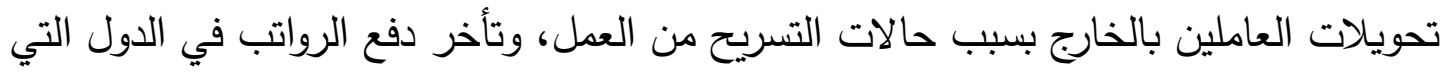

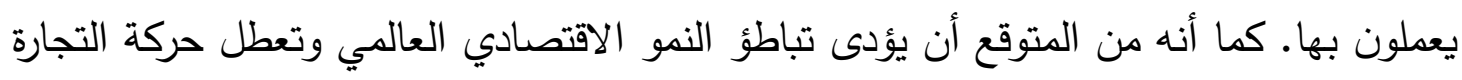

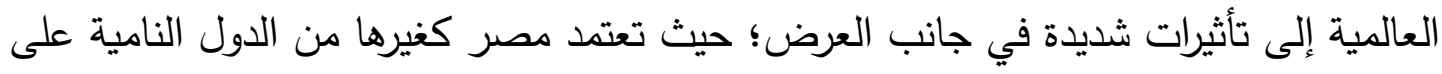

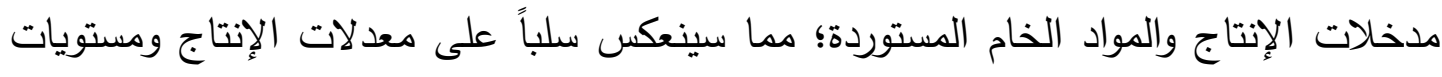

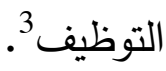

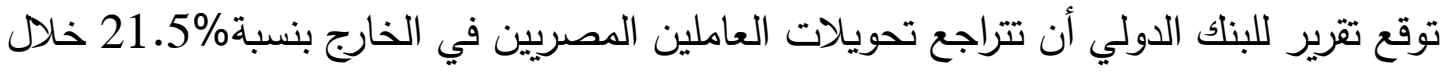

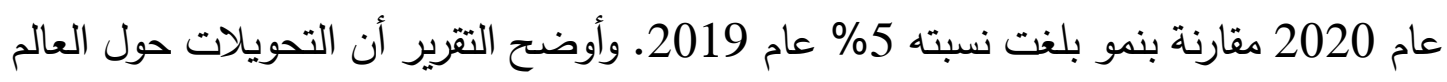
ستخفض بقيمة 142 مليار دولار في عام2020، وأن التحويلات في منطقة الشرق الأوسط

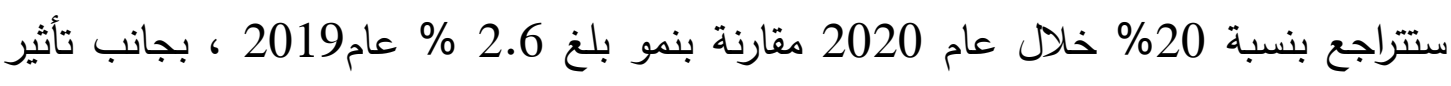
انخفاض أسعار البترول في دول الخليج. ويتوقع التقرير أن تتعافي التحويلات في المنطقة خلام خلاد

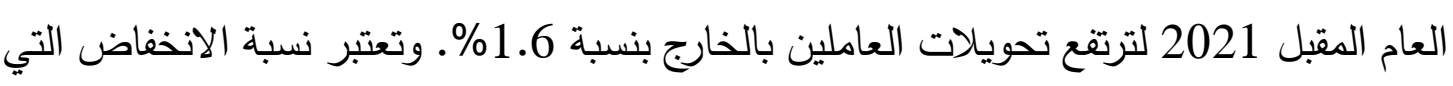

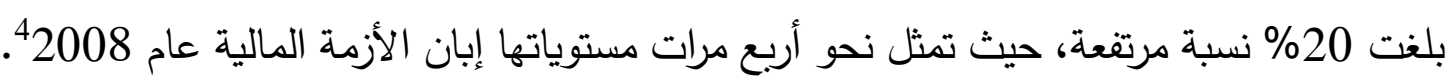

5- الأثر على إيرادات قناة السويس

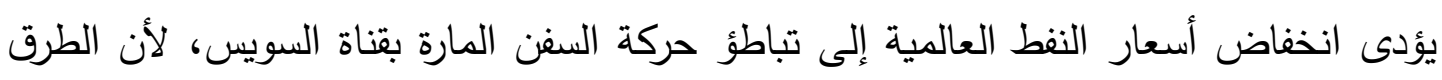

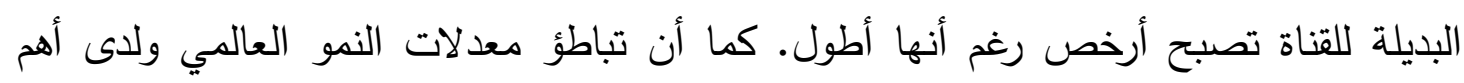

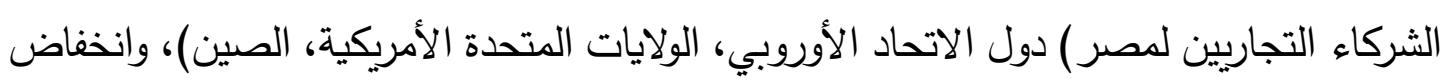
1 تقديرات البنك الدولي www.worldbank.org.database 2 الجهاز المركزي للتعبئة العامة والإحصاء، www.capmas.org https://unctad.org/en/pages/coronavirus.aspx مؤتمر الأمم المتحدة للتجارة والتنمية (الأونكتاد) 3

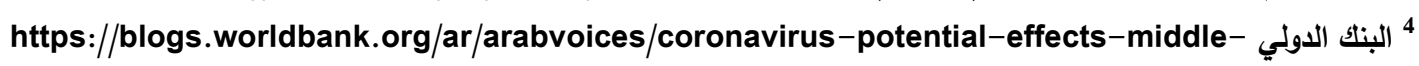
east-and-north-africa 
تدفقات التجارة العالمية، سيقلل من إيرادات قناة السويس. ومن المرجح أن يؤثر هبوط الإيرادات العامة المتحصل عليها من رسوم العبور في قناة السويس على الموازنة الحكومية.

وأشار تقرير غرفة التجارة الأمريكية بالقاهرة أنه مع الأزمة التي ضربت التجارة العالمية بشدة، تشهد ممرات التجارة الدولية بالفعل انخفاضات ملحوظة في حركة المرور والإيرادات، لذا من المتوقع أن تشهد القناة بعض التراجعات حيث أنه في شهر فبراير 2020، انخفض عدد سفن الحاويات المارة عبر القناة بنسبة 7.3 \% في حين تراجع عدد سفن الركاب والبضائع بنسبة 22.2 \% 2.3 \% على التوالي. وأن عبور سفن أقل في القناة يعنى انخفاض الرسوم المدفوعة، مما قد يؤدى إلى زيادة تقييد سيولة العملة الأجنبية بمصر ، إضافة إلى عجز الحساب الجاري والتأثير سلباً على سعر صرف الجنيه مقابل الدولار².

\section{6- الأثر على الاحتياطي من النقد الأجنبي}

انخفض احتياطي مصر من النقد الأجنبي خلال شهري مارس وأبريل 2020 بنحو 8.5 مليار دولار، وذللك بعد خروج نحو 15 مليار دولار من استثمارات الأجانب في أدوات الدين الحكومية، بحسب تقديرات وكالة موديز للتصنيف الائتماني، وأوضحت أنه يعتبر مستوى الاحتياطيات الدولية في وضع جيد يسمح بالتغلب على هذه التدفقات الخارجة على المدى القصير ، وسيقابل ذلك جزئيًا انخفاض الطلب المتوقع على الواردات في الفترة القادمة3. من المتوقع انخفاض سعر الجنيه المصري بنهاية عام 2020 في ظل فقدان مصر لجانب من مصادرها من العملات الأجنبية، مما سيؤدى إلى ضغوط على الجنيه المصري، علما بأن هناك مجموعة من العوامل قد تخفف الضغط على الجنيه المصري يتمثل أهمها في؛ انخفاض أسعار النفط، وزيادة مُحتملة في القدرة التتافسية للصادرات المصرية وخاصةً الصادرات الزراعية. إن الاقتصاد المصري لم يتأثر بشكل كبير من الأزمة الاقتصادية العالمية عام 2008 لاندماجه المحدود في الأسواق، وأدواته المالية وأساسياته الاقتصادية المحلية القوية، إلا أن التأثر بصدمة

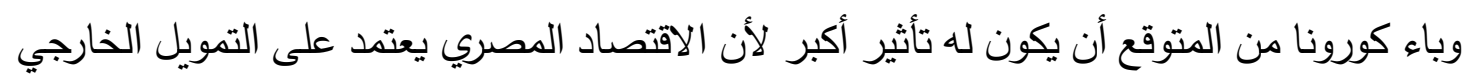
بصورة أكبر بالمقارنة مع عام 2008.

1 هيئة قناة السويس 1 American chamber of commerce in Egypt http://www.amcham.org.eg ${ }^{2}$ http://www.moodys.com وكالة موديز للتصنيف الائتماني 
ثالثاً: الإجراءات التي اتخذتها الحكومة للتعامل مع الأزمة

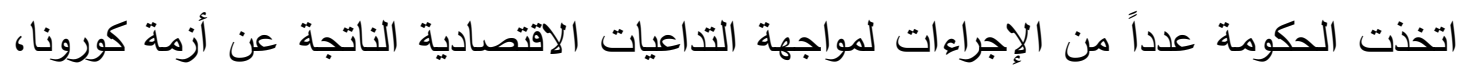
وتقديم المساعدة للقطاعات الأكثر تضررا في الاقتصاد المصري ويتضح ذلك من خلال ما يلي:

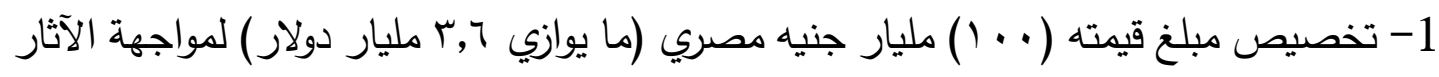

الاقتصادية لفيروس كورونا، ودعم الاقتصاد والسوق المالية. 2- دفع البنوك لزيادة القروض الموجهة إلى القطاع الخاص، وخاصة القطاعات الأكثر تضردًا. 3- قام البنك المركزي المصري بتخفيض الرسوم على عمليات السحب من أجهزة الصراف الآلي

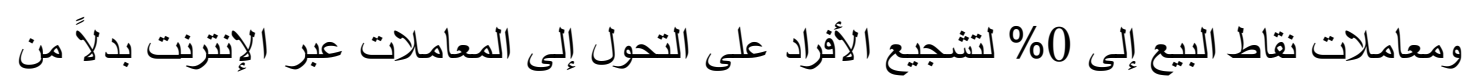

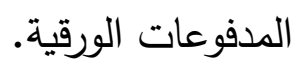
4- ضخ البنك المركزي 20 مليار جنيه في سوق الأسهم لتوفير تسهيلات للتحفيز النقدي وإتاحة

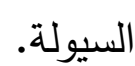
5- التصريح بإعفاءات ضريبية لصالح الشركات الصناعية والسياحية.

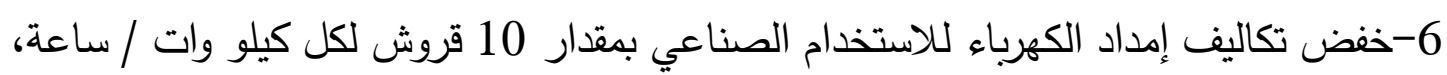
وقدرت مصادر حكومية أن هذه التخفيضات قد تتكلف حوالي 6 مليارات جنيه. 7-تخفيض سعر الغاز الطبيعي للصناعة إلى 4.5 دولار لكل مليون وحدة حرارية لتحفيز الإنتاج، مما أدى لتخفيض الأسعار بواقع 25 \% لشركات الأسمنت التي كانت تدفع 6 دولار لكل مليون لئل

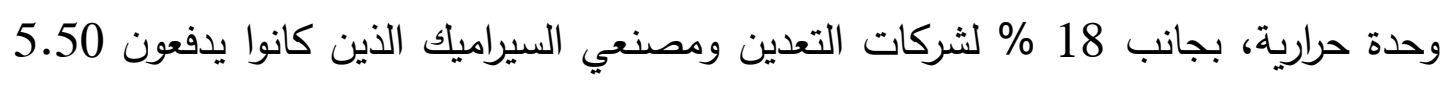
دولار لكل مليون وحدة. 8- خفضت لجنة السياسة النقدية بالبنك المركزي المصري أسعار الفائدة الرئيسية بمقدار 300

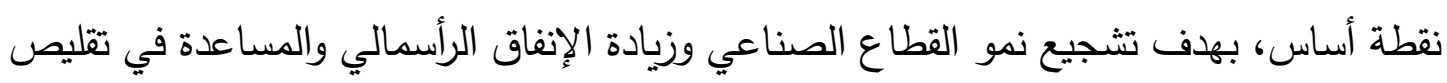
عجز الميزانية، والنظر إلى الإجراءات المالية التوسعية الجديدة وتحفيز الاستثمارات الأجنبية في سوق الأوراق المالية. 9-تأجيل أقساط ومدفوعات جميع القروض المصرفية للشركات وعملاء التجزئة لمدة ستة أشهر ، بما في ذلك الثركات الصغيرة والمتوسطة والمقترضون الأفراد. 10- زيادة التحويلات النقدية الموجهة إلى الأسر المعيشية الفقيرة، وتوجيه الدعم إلى قطاعات الاتفراد محددة، حيث تم توسيع نطاق قانون الضمان الاجتماعي والمعاشات من خلال صرف 27.6

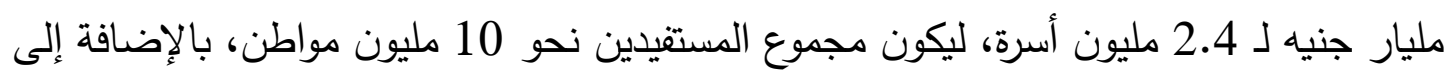
رفع المعاشات بنسبة 14 \% ابتداءً من عام 2021 للعاملين الموسميين الذين سجلوا عبر لحئر 
الإنترنت لاى وزارة القوى العاملة، وقامت بتوفير 500 جنيه. وقد تم تسجيل 130 ألف عامل حتى 25 مارس، فضلاً عن قرار تمديد تعليق الضريبة على الأراضي الزراعية لمدة عامين آخرين ـأ. قامت الحكومة المصرية والبنك المركزي المصري باتخاذ إجراءات استباقية وحاسمة للحفاظ على مكتسبات برنامج الإصلاح الاقتصادي، من خلال التقدم لصندوق النقد الدولي من أجل الحصول على حزمة مالية طبقاً لبرنامج أداة التمويل السريع، وبرنامج اتفاق الإستعداد الائتماني، واللذان

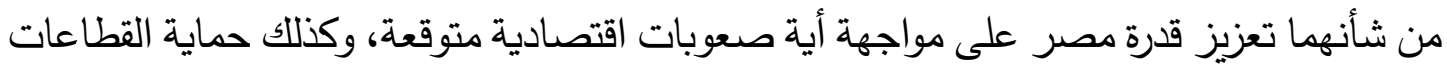
الأكثر عرضة لأضرار انتشار فيروس كورونا، وجرى الحصول على نصلى نحو 2.8 مليار دولار طبقا

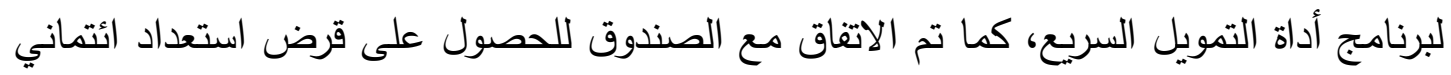

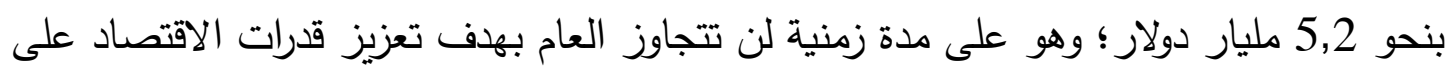

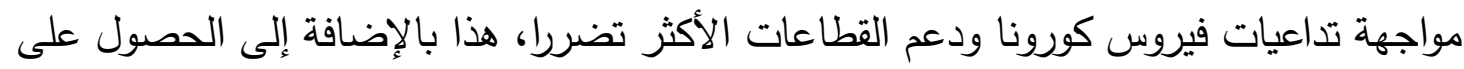

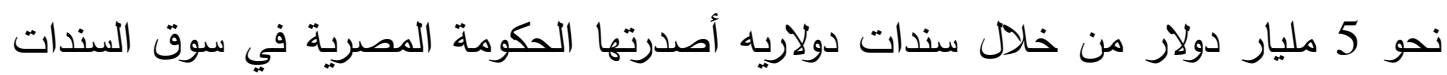
الدولية، كما يعمل البنك المركزي المصري دلى دلى إيجاد وسائل تمويلية جديدة أقل تكلفة لتعزيز

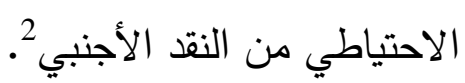

رابعاً: سياسات يمكن اتخاذها للحد من تداعيات كورونا

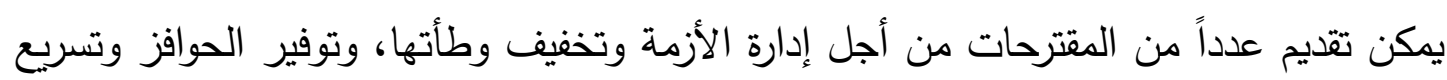
التعافي، وذللك على النحو التالي: 1- تشجيع السياحة المحلية من خلال تقديم عروض تشجيعية وتصميم حملة إعلامية مناسبة، وتخفيض رسوم المزارات السياحية خلا عل عام 2020. 2- تخفيض رسوم المطارات التي تخدم الوجهات السياحية خلال عام 2020. 3- استخدام مواقع التواصل الاجتماعي في الترويج لمنتجات المقصد السياحي المصري. 4- صياغة برامج جديدة للتسويق للمقاصد السياحية وتحفيز الطيران منخفض التكلفة. 5- التركيز على السوق العربي والأفريقي بعد انتهاء الأزمة لزيادة عدد السائحين.

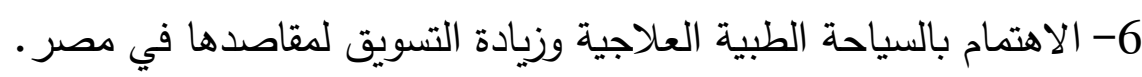
7- العمل مع القطاع السياحي الخاص على تلثيدية تشيع الابتكار ودعم رواد الأعمال والتوجه نحو السياحة الخضراء. 8- تخفيض ضريبة القيمة المضافة على الوجهات السياحية وتأجيل سداد الضريبة العقارية على المنشآت السياحية. 
9- تعليق كافة الالتزامات القانونية للمنشآت السياحية التي تواجه مشكلة في السيولة.

10-تفعيل صندوق الاستثمار السياحي لإعادة الهيكلة المالية للمشروعات السياحية.

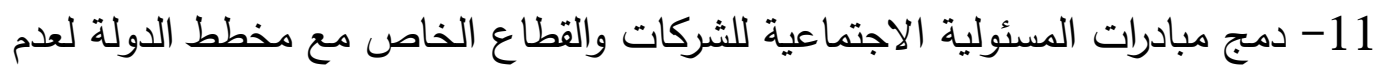

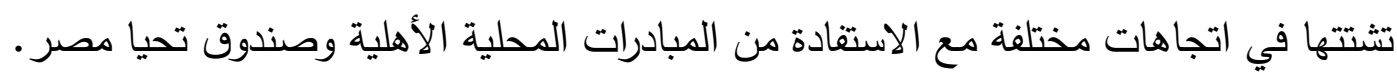
12- الاستعانة بمؤسسات التمويل الدولية والإقليمية في تقديم الدعم المالي والفني.

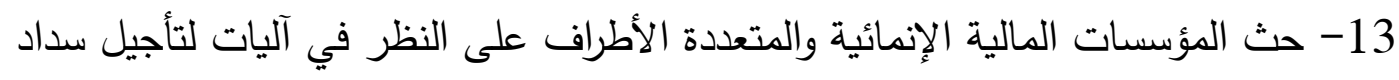
الديون وتعزيز الحيز المالي المتاح للدول متوسطة ومنخفضة الدخل، إضافة إلى تعزيز

الاستثمارات الاجتماعية وتقديم المنح والدعم الفني للدول حتى يتسنى لها مواجهة الأزمة.

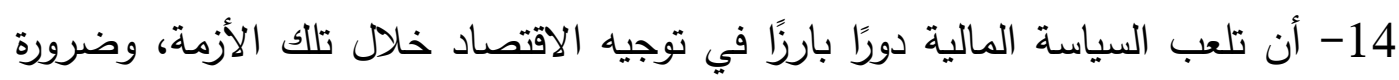

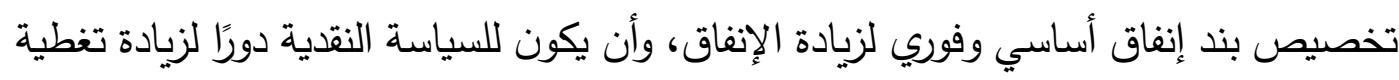

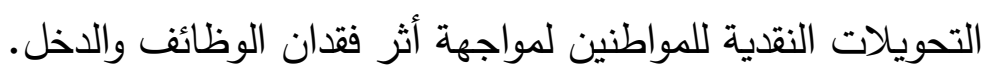

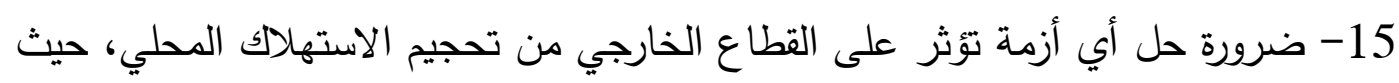

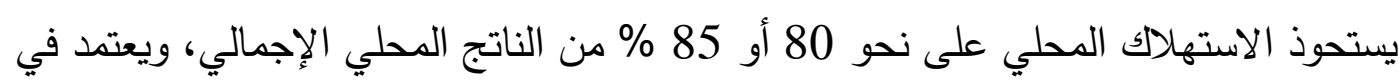

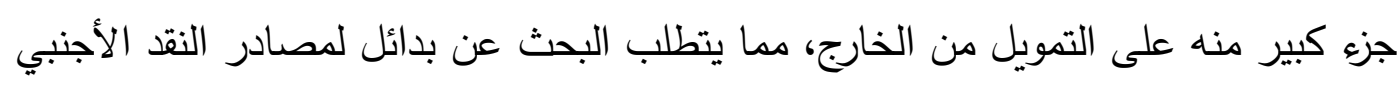

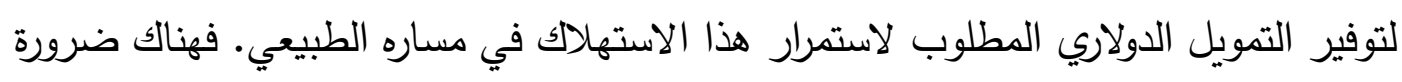

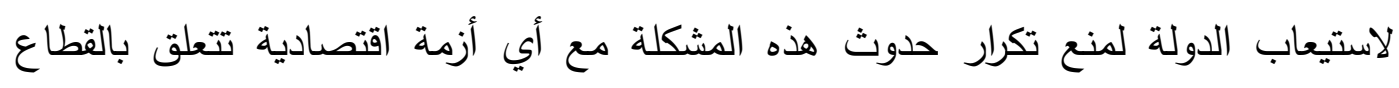

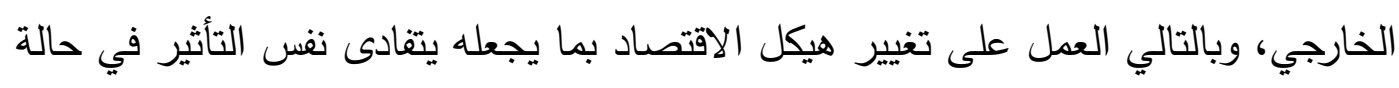

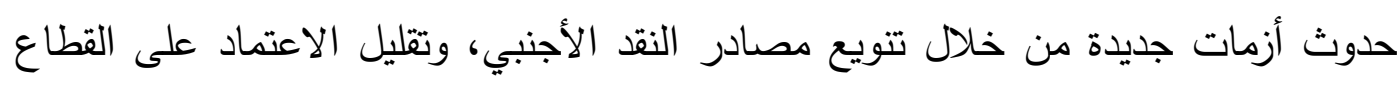
الخارجي.

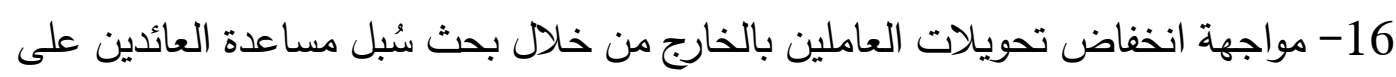
توظيف مدخراتهم في مشروعات صغيرة أو أوعية ادخارية مناسبة في البنوك، واستثمار طاقاتهم وخبراتهم في مجالات العمل المختلفة. 17- يمكن للبنك المركزي استخدام احتياطي النقد الأجنبي لتغطية عجز العملة الصعبة في

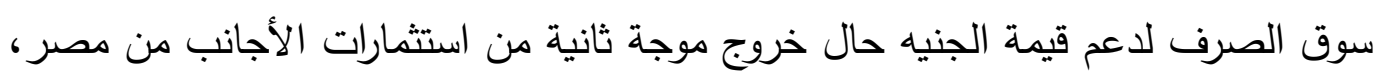

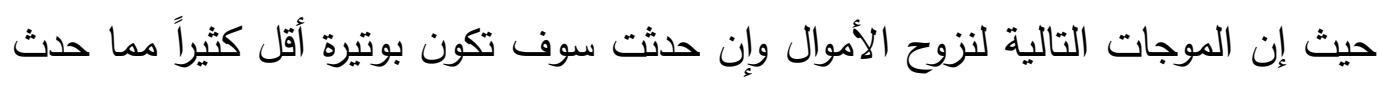

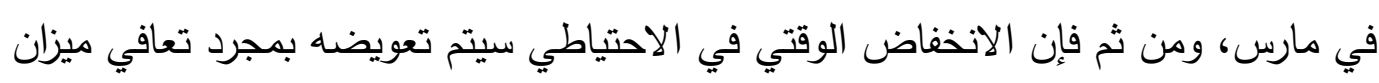

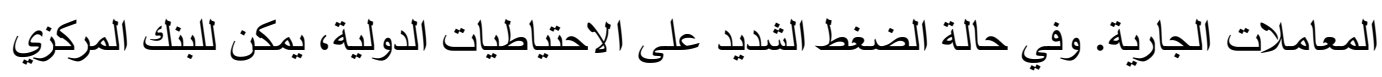
السماح للجنيه بالتحرك في حدود سعر استرشادي معين للحفاظ على معدلات التضخم. 
تسبب تباطؤ الاقتصاد العالمي نتيجة تفشي فيروس كورونا في انخفاض حجم السياحة الوافدة، وتراجع المتحصلات الواردة من قناة السوي، وكذلك انخفاض التحويلات المالية القادمة من المصريين العاملين في الخارج، وتستأثز المصادر الثلاث بنسبة ؛ 10\% من الناتج المحلي الإجمالي لمصر. ومن هذا المنطلق، يؤدي اختلال مصادر الاخل الأجنبي المشار إليها إلى تداعيات واسعة النطاق وتبعات طويلة المدى على الاقتصاد المصري، حيث تعتبر مصادر مصر من النقد الأجنبي من بين أكثر مظاهر تأثر الاقتصاد سلبًا بتداعيات أزمة كورونا خلال عامي 2020 و 2021. كما أن السياحة ستكون على رأس مصادر النقد الأجنبي المتأثرة، خاصة وأنها قد تستغرق فترة طويلة نسبيًا لاستعادة نشاطها بالكامل حتى بعد انتهاء أزمة كورونا كما هو الحال في غالبية دول العالم، هذا بالإضافة إلى تأثر تحويلات العاملين بالخارج وإيرادات قناة السويس، ومن المتوقع أيضا حدوث تراجع في تدفقات الاستثمار الأجنبي المباشر وحصيلة الصادرات. يبرز هذا الوضع أهمية تعزيز التعاون على المستوى العالمي من أجل إنهاء هذه الأزمة وتحسين مستوى الجاهزية والاستعداد للتجاوب مع المستقبل بشكل أفضل مع نظرة متفائلة للاقتصاد المصري في ظل توقعات المنظمات الدولية بأن تكون مصر من بين أفضل ثمان دول على مستوى العالم تحقق معدلات نمو إيجابية خلال عام 2020. 


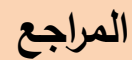

www.mped.gov.eg وزارة التخطيط والتمية الاقتصادية الجهاز المركزي للتعبئة العامة والإحصاء، www.capmas.org www.arkan- أسماء علي، التصدير في مصر السياسات والعوائق والغرص أركان للدراسات والأبحاث والنشر srp.com

www.gafi.gov.eg العيئة العامة للاستثمار والمناطق الحرة - www.capmas.org - مالجهاز المركزي للتعبئة العامة والإحصاء، http://www.cbe.org.eg البنك المركزي المصري، ibid.

http://www.moodys.com وكالة موديز للتصنيف الائتماني www.mped.gov.eg وزارة التخطيط والتمية الاقتصادية ibid. www.antiquities.gov.eg وزارة السياحة والآثار

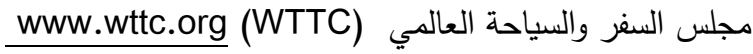
http://www.ilo.org/public/english/region/afpro/cairo منظمة العمل الدولية http://www.tfig.itcilo.org/contents/org/iata الاتحاد الدولي للنقل الجوي www.mti.gov.eg وزارة التجارة والصناعة American chamber of commerce in Egypt http://www.amcham.org.eg www.gafi.gov.eg الهيئة العامة للاستثمار والمناطق الحرة the institute of international finance http://www.iif.com/research/data www.worldbank.org.database تقديرات البنك الدولي الجهاز المركزي للتعبئة العامة والإحصاء، www.capmas.org https://unctad.org/en/pages/coronavirus.aspx مؤتمر الأمم المتحدة للتجارة والتتمية (الأونكتاد) https://blogs.worldbank.org/ar/arabvoices/coronavirus-potential-effects- البنك الدولي $\underline{\text { middle-east-and-north-africa }}$ www.suezcanal.gov.eg هيئة قناة السويس American chamber of commerce in Egypt http://www.amcham.org.eg http://www.moodys.com وكالة موديز للتصنيف الائتماني www.cbe.org.eg البنك المركزي المصري http://www.cabinet.gov.eg رئاسة مجلس الوزراء 